LAMBERG, MARKo 2009: Latinalainen paleografia. - Marko Lamberg, Anu Lahtinen \& Susanna Niiranen (toim.), Keskiajan avain s. 365-378. Suomalaisen Kirjallisuuden Seuran Toimituksia 1203. Helsinki: Suomalaisen Kirjallisuuden Seura.

RAJAмӓKI, SUvi 2015: Uppsalan käsikirjan messun piirteitä ja suhde muihin reformaatioajan messuteksteihin. Suomen kielen pro gradu -tutkielma. Turun yliopisto.

SKMI = Suomen kielen muistomerkkejä I. Monumenta linguae Fennicae 1. Mikael Agricolan Käsikirja ja Messu. Julkaisseet E. N. Setälä ja K. B. Wiklund. Suomalaisen Kirjallisuuden Seuran Toimituksia 82. Helsinki: Suomalaisen Kirjallisuuden Seura 1893.

Svensson, LARS 1974: Nordisk paleografi. Handbok med transkriberade och kommenterade skriftprov. Lundastudier i Nordisk språkvetenskap. Serie A NR 28. Lund: Studentlitteratur. http://www.guide_specialsamlingar. ub.lu.se/bilder/svensson_paleografi.pdf

Tekstuaalitieteiden sanasto $2010=\mathrm{HAL}^{-}$ lamaA, Olli - HeIKKIlä, TuOMas Karhu, Hanna - Katajamäki, Sakari - Kokko, Ossi - Pulkkinen, Veijo: Tekstuaalitieteiden sanasto. Helsinki: Suomalaisen Kirjallisuuden Seura. http://www.edith.fi/tekstuaalitieteidensanasto/. URN:NBN:fi:sks-201010061001 (1.8.2017).

VVKS = Virtuaalinen vanha kirjasuomi -internetsivusto. http://www.helsinki.fi/ vvks/aanne-_ja_muoto-oppi/sanastosta/ index.html\#a-23.6 (23.3.2018).

Walta, Ville 2017a: Kuvailu lähteestä Uppsala, Universitetsbibliotek, B 28. Magnus Eriksson's Landslag, Mikael Agricola's Manual. http://www.codicesfennici.fi (11.8.2017).

— 2017b: Kuvailu lähteestä Uppsala, University Library, T 387. Fragment of a Finnish Evangeliarum. http://www. codicesfennici.fi (11.8.2017).

\title{
Vanhaa kirjasuomea ongittelemaan
}

Mitä tarkoittaa vanhan kirjasuomen sana one? Milloin sana paahtaa on tullut kirjakieleen? Entä millä sanalla vanhassa kirjasuomessa kutsutaan siiliä? Minkälaisia adjektiiveja tai yhdysverbejä vanhassa kirjasuomessa esiintyy? Näihin ja moniin muihin kysymyksiin löytyy vastaus Vanhan kirjasuomen sanakirjasta (VKS).
Vanhan kirjasuomen sanakirja on laaja tietopaketti kirjoitetun suomen kielen vanhimmasta sanastosta 1540-luvulta aina 180o-luvun ensimmäiselle vuosikymmenelle. Tätä kirjoittaessani sanakirjaa on julkaistu $a$ :sta paistua-artikkeliin asti, yhteensä 39697 sana-artikkelia. Näistä päähakusana-artikkeleita on 29 388; loput 
ovat viiteartikkeleita, jotka on tehty sanan eri muodoista ja johtavat artikkeliin, jossa niitä käsitellään. Sanakirjasta on julkaistu kaksi painettua osaa (ks. tarkemmin tuonnempana), minkä jälkeen teos on muuttunut verkkojulkaisuksi. Verkkosanakirjaan materiaalia lisätään vuosittain aina marraskuussa, joten vuoden 2019 lopussa sanakirja on taas entistä laajempi.

\section{Sanakirjan aineisto ja esitystapa}

Vanhan kirjasuomen sanakirja pohjautuu keskeisimpään Ruotsin vallan aikana suomeksi julkaistuun kirjallisuuteen. Lisäksi sanakirjan aineistoihin kuuluu joitakin yhtenäisiä suomenkielisiä käsikirjoituksia, joita ei ole aikanaan painettu mutta joita pidetään kirjasuomen kehityksen näkökulmasta merkittävinä dokumentteina. Mukana on niin painotuotteiden esikoinen, Agricolan Abckiria, jonka ensimmäinen painos on todennäköisesti vuodelta 1542, kuin säilyneistä käsikirjoituksista vanhimmaksi ja edellisen kanssa melko samanikäiseksi arvioitu Uppsalan evankeliumikirjan katkelma. Hengellisen kielen aineistoja ovat myös esimerkiksi eri raamatunkäännökset, postillat eli saarnakokoelmat sekä virsikirjat. Lakikieltä edustavat niin laajat maan- ja kaupunginlakien suomennokset kuin lukuisat asetuksetkin, joiden aihepiirit ulottuvat ylellisyystarvikkeista kupan leviämiseen ja lumppujen keräämisestä torikaupan järjestämiseen. Tietokirjallisuutta edustavat muiden muassa sanomalehti Suomenkieliset TietoSanomat, joka oli ensimmäinen suomenkielinen sanomalehti ja ilmestyi hetken aikaa vuosina $1775-1776$, sekä vuodesta 1705 asti julkaistujen almanakkojen kirjalliset liitteet, joissa käsiteltiin esimerkiksi maanviljelyä ja reformaattori Martin Lutherin elämänvaiheita.

Vanhan kirjasuomen sanakirja on sitaattisanakirja. Se siis esittelee vanhan kirjasuomen sanastoa aineistosta poimittu- jen lainausten avulla. Lainaukset on valittu niin, että ne edustaisivat mahdollisimman monipuolisesti sanan eri merkityksiä ja käyttötapoja sekä siitä käytettyjä erilaisia variantteja. Mukaan on otettu esimerkkejä eri vuosikymmeniltä, eri kirjoittajien teksteistä ja eri tekstilajeista. Lainauksissa pyritään alkuperäistä tekstiä tiivistäen tuomaan mahdollisimman hyvin esiin sanaartikkelissa käsitelty sana ja sen kannalta keskeinen tekstiympäristö. Sitaattisanakirjana VKS valaisee siis laajasti sanojen käyttöhistoriaa, ja sen kautta avautuu laajempiakin näkymiä kielen kehitykseen ja variaatioon niin morfologian, syntaksin kuin ortografiankin osalta.

Verkossa julkaistavan sanakirjan kukin päähakusana-artikkeli sisältää hakusanan, mahdolliset sanasta käytetyt eri morfologiset variantit ja sanaluokkamerkinnän sekä aikajanan, joka antaa nopeasti yleiskuvan siitä, milloin sanaa on käytetty. Lisäksi sana-artikkelissa on vanhan kirjasuomen aikaisista sanakirjoista poimittuja tietoja sekä niiden jälkeen muita aineistositaatteja sisältävä osio tai jompikumpi mainituista. Tarpeen mukaan sana-artikkelissa on myös nykykielisiä selitteitä ja esimerkit on voitu jakaa merkitysryhmiin; alihakusanoina esitetään kiteytyneitä ilmauksia, joissa sana esiintyy. Useissa artikkeleissa on vielä viimeisenä yhdyssanaluettelo, jossa on mainittu kaikki ne yhdyssanat, joissa päähakusana on perusosana.

Verkkosanakirjan artikkeleihin voi tutustua usean eri näkymän kautta: oletusnäkymänä on Koko artikkeli -näkymä, mutta halutessaan sanakirjan käyttäjä voi valita Jäsennys-näkymän, jossa näkyy vain artikkelin jäsennys eli merkitysryhmät ja alihakusanat selitteineen ilman esimerkkejä, tai Ensimmäiset esimerkit -näkymän, jossa näkyy jäsennyksen lisäksi kunkin ryhmän ensimmäinen esimerkki. Sanakirjaa on mahdollista myös selailla näytön vasemmassa laidassa olevan aakkos- ja sanalistan avulla. 
Yksittäistä sanaa klikkaamalla aukeaa sana-artikkeli, ja laidan listalla näkyy lisäksi kymmenen edeltävää ja kymmenen seuraavaa hakusanaa. Tällä hetkellä Vanhan kirjasuomen sanakirjan käyttöliittymä ei vielä ole responsiivinen, joten sanakirjaan on kätevintä tutustua isolla näytöllä.

\section{Setälän sanakirjaohjelmasta verkkosanakirjaan}

"Vanhemman kirjakielen sanakirja" on yksi niistä sanakirjoista, jotka E. N. Setälä mainitsi Suomalaisen Kirjallisuuden Seuran kokouksessa 12.2.1896 esittelemässään "Suomalaisen sanakirjatyön ohjelmassa" (Suomi 13 s. 92-95). Setälän ajatus alkoi konkretisoitua 1950-luvun lopulla, kun professori Martti Rapola aloitti sanakirjan esityöt, joihin kuului muun muassa aineiston kartoittamista, Rapolan omien sanapoimintojen järjestämistä ja sanaartikkelien rakenteen suunnittelua (ks. Rapola 1958: 56-66).

Alkuaan Vanhan kirjasuomen sanakirjasta kaavailtiin 4-6-osaista sarjaa. Sanakirjasta on painettuna ilmestynyt kuitenkin vain kaksi ensimmäistä osaa (VKS 1 v. 1985 ja VKS 2 v. 1994), jotka yhdessä kattavat aakkosvälin $a-k$. Vuonna 2012 päädyttiin siihen, että sanakirjaa jatketaan verkkojulkaisuna. Verkkosanakirjan $m$-alkuiset artikkelit sisältävä näytejakso julkaistiin vuonna 2014, minkä jälkeen sanakirjaa on laajennettu vuosittain. Tällä hetkellä toimitus kirjoittaa $p$-alkuisia artikkeleita.

Vuonna 2019 sanakirjan toimitus on suurempi kuin koskaan historiassaan ja uutta sisältöä sanakirjaan tehdään suurelta osin Koneen Säätiön rahoituksen turvin: kahdeksasta toimittajasta kuusi työskentelee sen rahoituksella. Keväällä 2018 säätiö myönsi rahoituksen viisivuotiskaudelle 2019-2023. Se on tukenut sanakirjan toimittamista vuoden 2012 alusta lähtien. Sanakirjan toimittami- sen ohessa toimitus muun muassa julkaisee Elävät päät -blogia (ks. https://www. kotus.fi/nyt/kotus-blogi/elavat_paat) ja vastaa vanhaa kirjasuomea koskeviin yleisökysymyksiin.

Kotimaisten kielten keskuksen vanhaa kirjasuomea koskevaan toimintaan voi tutustua osoitteessa https://www.kotus.fi/sanakirjat/vanhan_kirjasuomen_ sanakirja. Itse sanakirja löytyy osoitteesta http://kaino.kotus.fi/vks/.

\section{Perushaku}

Verkkosanakirjassa on sekä yksinkertainen perushaku että tarkennettu haku. Yksinkertaisella haulla hakukenttään kirjoitetaan haettava merkkijono, joka voi olla koko sana tai vain osa sanan alusta, keskeltä tai lopusta. Hakutuloksena saa luettelon sana-artikkeleista, jotka täyttävät hakuehdon. Tätä hakua käytettäessä on hyvä muistaa, että sanakirjan artikkelien hakusanoitus noudattaa nykykielen ortografiaa ja päähakusanat ovat nykykielisessä ja joskus myös nykykielistetyssä muodossa riippumatta siitä, esiintyykö hakusanan mukaisia muotoja lähdeaineistossa. Kirjoittamalla hakukenttään vaikkapa merkkijonon one ja valitsemalla sanalistasta ensimmäisen esiintymän pääsee one-artikkeliin. One on adjektiivi, joka esiintyy vanhassa kirjasuomessa merkitsemässä muun muassa heikkoa tai kelvotonta ihmistä tai mitätöntä asiaa. Seuraavat kaksi esimerkkiä on poimittu sanaartikkelista:

B1 Ps 22 jälk. Jotca tuhwas owat, owat waiwaiset ja onhet, jotca waiwalla ja murhella eläwät - caicki pitä Christusta rucoileman (A III 241 reun. halpat)

Holl $1745 \quad 243$ wiellä [!] ne caickein onhemmat synnin tomutkin, joita emme ennen syndinä pitänetkän, tulewat nyt ilmei 
Esimerkkien alussa olevaa lähdettä ilmaisevaa koodia klikkaamalla pääsee verkkosanakirjassa tarkistamaan, mikä lähde on kyseessä. Esimerkit on poimittu vuonna 1642 julkaistusta Bibliasta ja 1745 julkaistusta David Hollatzin kirjasta Armon Järjestys Aututehen. Biblialainauksen loppuun on nostettu vertailuun Agricolan vastaavassa Dauidin Psaltarin reunahuomautuksessa käytetty sanavastine halpat.

Sitaattien ja merkityksen lisäksi sanaartikkeli paljastaa hakusanasta monenlaista muutakin, kuten erilaiset morfologiset ja ortografiset variantit, sanaluokan, vanhoista sanakirjoista poimittuja synonyymejä sekä lukijoita usein kiinnostavan tiedon sanan kirjallisesta ensiesiintymästä. Paahtaa-artikkelissa vanhin esiintymä on vuonna 1781 julkaistussa asetuksessa:

[Pannun] sille äärelle, josa walkia kowemmasti päälle pahtaa, pannan yxi lauta ylitze kuohumista estämään.

\section{Tarkennettu haku}

Tarkennetussa haussa hakuehtoja voi määritellä hyvinkin tarkkaan: Hakusanojen lisäksi voi hakea muista sanaartikkelin osista, kuten merkityksenselitteistä ja esimerkeistä. Halutessaan voi etsiä vain jonkin tietyn sanaluokan edustajia.

Kun tarkennetussa haussa kirjoittaa merkityksenselitteistä-kenttään sanan siili, löytyy siiliä merkitsevä artikkeli iiliskotti. Kun taas valitsee sanaluokaksi pudotusvalikosta adjektiivia tarkoittavan lyhenteen $a$., saa tulokseksi listan adjektiiviartikkeleista, joita on yhteensä 5544 kappaletta. Viimeisenä listalla on tällä hetkellä viiteartikkeli paistavainen. Se viittaa paistava-artikkeliin, jossa myös -inen-loppuinen adjektiivi on käsitelty. Sana esiintyy jo Agricolan Uuden testa- mentin suomennoksessa sekä myöhemmin Biblioissa:

A II 258 (B ${ }^{1-4}$ Jh 5:35) [Johannes] oli palauainen ia paistauainen.

Esimerkkihakua voi käyttää apuna, kun vanhan kirjasuomen tekstejä lukiessaan törmää johonkin outoon sananmuotoon. Niinpä esimerkiksi nähtyään one-sanan $h$ :llisen onhe-muodon voi hakea sitä, jolloin löytyy artikkelit, joissa muoto esiintyy. Tällaisia ovat one ja oneellinen. Kun kirjainjonon perään lisää jokerimerkin $\left({ }^{*}\right)$, löytyvät kaikki artikkelit, joissa esiintyy kirjainyhdistelmällä onhe alkavia sanoja. Edellisten lisäksi onhealkuisia sanoja esiintyy muun muassa artikkeleissa oneesti ja onheus.

Esimerkkihaussa voi käyttää myös säännöllisiä lausekkeita, mikä mahdollistaa useampien eri kirjoitusasujen hakemisen samalla kertaa. Esimerkiksi merkkijonolla onh?e. ${ }^{\star}$ saa esiin kaikki artikkelit, joiden esimerkistössä on onetai onhe-alkuisia sanoja. Tällaisia artikkeleita on 39, muiden muassa one, onnellinen, onellinen sekä haahti-artikkeli, jonka esimerkistössä esiintyy Florinuksen sanakirjasta poimittu haaxi-sanan latinankielinen vastine navis oneraria.

Tarkennetussa haussa eri hakuehtoja voi myös yhdistellä, mikä mahdollistaa melko monimutkaisiakin hakuja. Esimerkiksi kaikki yhdysverbiartikkelit löytää hakemalla jokerimerkillä * yhdyssanojen perusosista ja valitsemalla sanaluokaksi verbin. Tulokseksi saa 391 sana-artikkelin listan, jolla on muun muassa korville lyömistä merkitsevä korvapuustella ja oraalla olevan kylvömaan jyrällä tiivistämistä merkitsevä orasjyrästää.

Tarkennetun haun lomakkeella viimeisenä vaihtoehtona on koko artikkelista hakeminen. Tämä haku kohdistuu artikkelin kaikkiin muihin elementteihin kuin hakusanoihin, sanaluokkiin ja käyttöaloihin, joille on omat, helpommat haut. 
Koko artikkelista hakuun ei voi yhdistää muita hakuvaihtoehtoja. Sanakirjan käyttöohjeissa tätä hakua suositellaan "vielä viimeisenä oljenkortena, mikäli muut haut eivät tuottaneet tulosta".

\section{Tutkimuksen avuksi ja aineistoksi}

Vaikka verkkosanakirjan haut rajoittuvat tällä hetkellä vain välille $a$-paistua, tarjoaa sanakirja silti paljon tietoa ja tutkimusaineistoakin vanhasta kielestä kiinnostuneille. Vanhan kirjasuomen sanakirjasta voi ongitella, kurkistella, arvata tai vaikka oppia - kuten vanhan kirjasuomen aikaan olisi voitu kirjoittaa vanhan kirjasuomen sanaston vaiheita.

Sanakirja on systemaattinen aineskokoelma, joka laajentaa käyttäjänsä tietopiiriä ja voi sitä kautta johtaa erilaisten ongelmien ratkaisuun, kuten Rapola (1958) kaavaili. VKS:n avulla selviävät niin nykykielelle kokonaan vieraiden kuin tuttujen mutta toisinaan vieraassa yhteydessä käytettyjen vanhan kirjakielen sanojenkin merkitykset. Samalla tulevat tutuiksi myös vanhan kirjasuomen ortografiset ja muoto-opilliset piirteet, erilaiset kiteytyneet sanontatavat ja konneksiot ja sitaattien kautta myös laajemmin syntaktiset piirteet.

Sanakirjan sitaattien avulla käyttäjä pääsee tutustumaan Ruotsin vallan aikaiseen kieleen ja elämään, ja verkkosanakirjan monipuoliset hakuominaisuudet mahdollistavat jopa tutkimusaineiston kokoamisen. Sanakirja on oiva apuneuvo paitsi kirjakielen historiaan myös monien

1. Sanakirjan käyttäjän avuksi on tehty myös useita opastusvideoita, joihin pääsee tutustumaan sanakirjan yläpalkin ohjeet-sanan takaa aukeavalta sivulta. muiden alojen historiaan tutustuttaessa ja palveleekin paitsi kielentutkijoita myös esimerkiksi teologeja ja kulttuuri- ja aatehistorioitsijoita - tavallista kielestä kiinnostunutta käyttäjää unohtamatta.

MARIA LEHTONEN

etunimi.sukunimi@kotus.fi

Kirjoittaja on Vanhan kirjasuomen sanakirjan toimittaja ja jatko-opiskelija Turun yliopiston suomen kielen oppiaineessa.

\section{Lähteet}

Rapola, Mart Ti 1958: Vanhan Kirjasuomen sanakirjan ohjelmakysymyksiä.

- Virittäjä 62 s. 56-66.

Suomi. Suomalaisen Kirjallisuuden Seuran keskustelemukset 1895-1896. Helsinki: Suomalaisen Kirjallisuuden Seura. https://digi.kansalliskirjasto.fi.

Vanhan kirjasuomen sanakirja. 2014. Kotimaisten kielten keskuksen verkkojulkaisuja 38. Helsinki: Kotimaisten kielten keskus. Verkkojulkaisu HTML. URN:NBN:fi:kotus201435, ISSN: 2323337o. http://kaino.kotus.fi/vks. Jatkuvasti päivitettävä julkaisu. Päivitetty 23.11.2018 (11.2.2019).

VKS 1 = Vanhan kirjasuomen sanakirja. Ensimmäinen osa, A-I. Päätoimittaja Esko Koivusalo. Kotimaisten kielten tutkimuskeskuksen julkaisuja 33. Helsinki: Kotimaisten kielten tutkimuskeskus \& Valtion painatuskeskus 1985.

VKS 2 = Vanhan kirjasuomen sanakirja. Toinen osa, J-K. Päätoimittaja Maija Länsimäki. Kotimaisten kielten tutkimuskeskuksen julkaisuja 33. Helsinki: Kotimaisten kielten tutkimuskeskus \& Painatuskeskus 1994. 